\title{
Quantal Analysis Reveals a Functional Correlation between Presynaptic and Postsynaptic Efficacy in Excitatory Connections from Rat Neocortex
}

\author{
Neil R. Hardingham, ${ }^{1,2}$ Jenny C. A. Read, ${ }^{1,3}$ Andrew J. Trevelyan, ${ }^{1,3,4}$ J. Charmaine Nelson, ${ }^{1}$ J. Julian B. Jack, ${ }^{1,5}$ \\ and Neil J. Bannister ${ }^{1,6}$ \\ ${ }^{1}$ The University Laboratory of Physiology, Oxford University, Oxford, OX1 3PT, United Kingdom, ${ }^{2}$ The School of Biosciences, Cardiff University, Cardiff, \\ CF10 3AX, United Kingdom, ${ }^{3}$ Institute of Neuroscience, Medical School, Newcastle University, Newcastle upon Tyne, NE2 4HH, United Kingdom, ${ }^{4}$ The \\ Institute for Ageing and Health, Newcastle University, Newcastle upon Tyne, NE1 7RU, United Kingdom, ${ }^{5}$ Wolfson Institute of Biomedical Research, \\ University College London, London, WC1E 6BT, United Kingdom, and ' Medical Research Council Centre for Synaptic Plasticity, Department of Anatomy, \\ School of Medical Sciences, University of Bristol, Bristol, BS8 1TD, United Kingdom
}

At many central synapses, the presynaptic bouton and postsynaptic density are structurally correlated. However, it is unknown whether this correlation extends to the functional properties of the synapses. To investigate this, we made recordings from synaptically coupled pairs of pyramidal neurons in rat visual cortex. The mean peak amplitude of EPSPs recorded from pairs of L2/3 neurons ranged between $40 \mu \mathrm{V}$ and $2.9 \mathrm{mV}$. EPSP rise times were consistent with the majority of the synapses being located on basal dendrites; this was confirmed by full anatomical reconstructions of a subset of connected pairs. Over a third of the connections could be described using a quantal model that assumed simple binomial statistics. Release probability $\left(P_{\mathrm{r}}\right)$ and quantal size $(Q)$, as measured at the somatic recording site, showed considerable heterogeneity between connections. However, across the population of connections, values of $P_{\mathrm{r}}$ and $Q$ for individual connections were positively correlated with one another. This correlation also held for inputs to layer 5 pyramidal neurons from both layer $2 / 3$ and neighboring layer 5 pyramidal neurons, suggesting that during development of cortical connections presynaptic and postsynaptic strengths are dependently scaled. For $2 / 3$ to $2 / 3$ connections, mean EPSP amplitude was correlated with both $Q$ and $P_{\mathrm{r}}$ values but uncorrelated with $N$, the number of functional release sites mediating the connection. The efficacy of a cortical connection is thus set by coordinated presynaptic and postsynaptic strength.

\section{Introduction}

The overall strength of synaptic connections between neurons is determined by multiple factors, some being structural (Walmsley et al., 1998; Rollenhagen and Lübke, 2006). Both the size and the number of boutons (presynaptic elements) mediating a synaptic connection between neurons in the CNS can vary considerably (Walmsley et al., 1998; Rollenhagen and Lübke, 2006). It is now widely accepted that quantal release of transmitter normally occurs at presynaptic active zones (Katz, 1969). In the hippocampus and neocortex, most excitatory synaptic boutons are fairly small and usually have only a single active zone (Peters et al., 1990; Schikorski and Stevens, 1997, 1999). Nevertheless, in boutons with a single active zone, presynaptic strength or release probability $\left(P_{\mathrm{r}}\right)$ may be correlated with the area of active zones, which can vary considerably (Atwood and Marin, 1983; Schikorski and Stevens, 1997; Murthy et al., 2001).

Received July 8, 2009; revised Sept. 2, 2009; accepted Nov. 27, 2009

This work was funded by the Wellcome Trust and the Medical Research Council. We thank Guy Major and Claire Cheetham for helpful comments.

Correspondence should be addressed to Neil R. Hardingham: The School of Biosciences, Cardiff University, Museum Avenue, Cardiff, CF10 3AX, UK. E-mail: hardinghamnr@cardiff.ac.uk.

D01:10.1523/JNEUROSCI.3244-09.2010

Copyright $\odot 2010$ the authors $\quad 0270-6474 / 10 / 301441-11 \$ 15.00 / 0$
Another factor that would be expected to influence synaptic efficacy is the postsynaptic location of the synapse on the dendritic tree. Cable theory predicts that more distal synapses should be less efficacious at the soma as a result of cable attenuation (Rall, 1960; Jack et al., 1981, 1994; Stuart and Spruston, 1998). However, it is possible that, in some neurons, there are compensatory mechanisms to boost the signal of more distal synapses (Andrasfalvy and Magee, 2001; Nicholson et al., 2006). Indeed, studies have shown that, in some neuronal classes, the size of the postsynaptic density (PSD) is larger at increasing distances from the soma (Triller et al., 1990; Alvarez et al., 1997).

There is evidence that the PSD is normally coextensive with the presynaptic active zone. Quantitative studies have shown strong correlations between coextensive PSD and active zone areas (Schikorski and Stevens, 1997, 1999) and also between the number of AMPA receptors and the area of the PSD (Nusser et al., 1998; Takumi et al., 1999; Tanaka et al., 2005). At mature synapses, under conditions of postsynaptic saturation (Wall and Usowicz, 1998), the size of the quantal current at the synapse is therefore expected to be related to the area of the PSD and hence to the area of the active zone (Lim et al., 1999). This leads to the prediction that release probability (presynaptic efficacy) for a given synapse is correlated with the synaptic current (postsynaptic efficacy). 
The purpose of this study was to explore this prediction in cortex, using paired electrophysiological recordings of synaptically connected pyramidal neurons and subsequent quantal analysis of the recordings (Hardingham et al., 2006, 2007). The majority of synaptic contacts in these connections have been shown to be located relatively proximal to the soma on basal or apical oblique dendrites (Koester and Johnston, 2005; Feldmeyer et al., 2006). EPSP amplitudes recorded at the soma of cortical pyramidal neurons have been shown to be relatively insensitive to the location of the synapse on the basal dendritic tree (Nevian et al., 2007). The major finding of this study is a strong correlation between release probability and quantal size $(Q)$ at excitatory connections in developing rat visual cortex.

\section{Materials and Methods}

Slice preparation and intracellular recording. Recordings were made from brain slices taken from 19- to 27-d-old Sprague Dawley rats. Details of slice preparation and intracellular recording have been given previously (Hardingham et al., 2006). Recordings were made between pairs of layer 2/3 (L2/3) pyramidal neurons, between pairs of layer 5 (L5) pyramidal neurons, and pairs of pyramidal neurons, one in L2/3 and one in L5. A synaptically connected pair of cells was found in 1 of 7 pairs tested for L2/3 neurons and L5-L5 neurons and 1 of 10 pairs of neurons for L2/3 to L5 connections. When testing L2/3 to L5, neurons were selected in the same vertical column of cortex. In some experiments, $0.5 \%$ biocytin was included in the recording pipette for morphological reconstructions after recording. Series resistance was estimated by bridge balance and ranged between 20 and $40 \mathrm{M} \Omega$. Both series resistances and pipette capacitances were checked and compensated for during recordings, and experiments were discontinued if the series resistance changed by $>20 \%$ during a recording. The mean resting membrane potentials were $-69 \pm 6 \mathrm{mV}$ (mean $\pm \mathrm{SD})$ for L2/3 neurons $(n=287)$ and $-67 \pm 4 \mathrm{mV}$ for L5 neurons $(n=62)$. Postsynaptic responses were recorded in the currentclamp configuration because EPSPs are less sensitive to changes in the electrode series resistance in this configuration and suffer less differential attenuation of peak amplitude with electrotonic distance when compared with voltage-clamp recording (Major, 1993). Once a synaptic connection had been identified, single action potentials were induced in the presynaptic cell at $0.1 \mathrm{~Hz}$ by injection of short (5-10 ms) pulses of depolarizing current. Postsynaptic responses were amplified using an AxoProbe 1A amplifier (Molecular Devices), low-pass filtered at $2 \mathrm{kHz}$, digitized at $5 \mathrm{kHz}$ using a CED 1401 analog-to-digital board (Cambridge Electronic Design), and recorded on a personal computer for analysis offline. Postsynaptic neurons were held at membrane potentials more negative than $-60 \mathrm{mV}$ to ensure that EPSPs were dominated by AMPA receptor-mediated currents (holding current was rarely necessary). Recordings were made at either laboratory temperature $\left(23-26^{\circ} \mathrm{C}\right)$ or body temperature $\left(36^{\circ} \mathrm{C}\right)$. Miniature EPSPs (mEPSPs) were recorded in the presence of tetrodotoxin (TTX) $(1 \mu \mathrm{M})$ and picrotoxin (PTX) $(100 \mu \mathrm{M})$, which were added to the artificial CSF. mEPSP amplitudes were measured as described previously (Hardingham and Larkman, 1998).

Analysis of EPSP data. Only recordings that remained stable (for stability criteria, see Hardingham et al., 2006) for at least 100 consecutive trials of recording were included in the dataset. In all cases, we selected the earliest possible stable period of data to avoid analyzing data in which washout may have caused depression of quantal size or release probability (Larkman et al., 1997). In these stability criteria, both mean EPSP amplitude and SD were required to remain within $15 \%$ of their initial values because previous studies have shown that significant drifts in quantal size over time, which were sometimes associated with inverse changes in release probability, had no net effect on the mean amplitude but produced an unstable SD (our unpublished observations) (Larkman et al., 1997). The number of consecutive stable trials per connection ranged from 100 to 1200 . For each connection, we calculated the mean EPSP amplitude and the failure rate, determined by visual inspection of individual sweeps. The amplitude of each EPSP and associated background noise for the recording was measured offline according to the methods given previously (Hardingham et al., 2006, 2007). The mean noise SD was subtracted from the EPSP SD using the following equation: $(\text { EPSP SD })^{2}=(\text { SD of combined EPSP }+ \text { noise })^{2}-(\text { noise SD })^{2}$. The coefficient of variation (CV) of the EPSP amplitude was calculated for each connection as being the SD divided by the mean amplitude.

Quantal analysis. Quantal analysis of stable periods of recording was performed as described previously (Hardingham et al., 2006, 2007). After fitting the quantal parameters, an array of tests were run to ensure that the fit was considered statistically "adequate", i.e., the probability that the distribution of EPSP amplitudes could have been produced by the fitted model (Hardingham et al., 2006). Although for most connections we were only able to use relatively small numbers of trials because of stability criteria (mean number of trials was $166 \pm 45$ ), in some connections, quantal peaks were evident from EPSP amplitude distributions taken from much longer concurrent periods of recording (supplemental Fig. 1, available at www.jneurosci.org as supplemental material). Estimates of $Q$ from these longer numbers of trials were comparable with those derived from the shorter, stable epochs of trials $(n=10$, all $p>0.05)$ (supplemental Fig. 1, available at www.jneurosci.org as supplemental material) but were associated with significantly higher values of quantal variance $(n=10, p<0.001)$ (supplemental Fig. 1, available at www.jneurosci.org as supplemental material). We included a direct current (DC) offset parameter in the model optimizer $(S)$ to accommodate a synaptic failure peak offset from zero, which can arise as a result of extracellular field effects (Stricker et al., 1996). The mean offset value from the models was $-13 \pm 40 \mu \mathrm{V}$ for the $\mathrm{L} 2 / 3$ connections $(n=50)$ and $8 \pm 63 \mu \mathrm{V}$ for the L 5 inputs $(n=12)$. As an additional check on the measured quantal size for datasets, we applied two additional tests. The first was to divide the datasets into two halves, in the order in which it was collected. Models were then fitted to each half [constraining $N$ (number of functional release sites) to that found for the dataset as a whole] to obtain a value for $Q$. The values of quantal size for the first and second half $\left(Q_{1}, Q_{2}\right)$ of the dataset were then compared. If $\left[\left(Q_{1}-Q_{2}\right) / Q_{\text {whole }}\right]$ exceeded $\pm 15 \%$, the dataset was rejected on the grounds of a likely instability of quantal size over the recording, which might lead to an overestimate of quantal variability. We also repeated the first half/second half comparison for derived values of quantal content $\left(m=N^{*} P_{\mathrm{r}}\right), P_{\mathrm{r}}$, and $N$. All plots had linear regressions close to the diagonal with strong correlations between first and second half values (all $p<0.001$; data not shown). The second test used an autocorrelation (AC) method (Stratford et al., 1997) to ensure that the peaks in the amplitude frequency histogram were statistically robust (supplemental Fig. 1, available at www.jneurosci.org as supplemental material) and hence that the peaks in the histogram were not a sampling artifact derived from a smooth underlying distribution. We compared the autocorrelation of the dataset with that of simulated Monte Carlo distributions from a smooth unimodal fit to the dataset to obtain a probability that the peaks did not arise from random sampling, with a conventional threshold of 0.05 (Stratford et al., 1997). The average probability of incorrectness $\left(p_{i}\right)$ of the $\mathrm{L} 2 / 3$ to $\mathrm{L} 2 / 3$ connections that passed the test was $0.01 \pm 0.02$ and, for the layer 5 inputs, it was $0.02 \pm$ 0.01 . Just under half of the L2/3 to L2/3 connections (20 of 50 ) had $p_{i}$ values of $<0.001$. Quantal parameters derived from these 20 connections were representative of the overall population of the 50 connections analyzed (all comparisons $p>0.05$ ). Of the 47 connections that failed the fitting procedure, 28 failed the AC scoring (i.e., $p_{i}>0.05$ ), and 12 failed the first half/second half consistency in $Q$.

For 118 of our 180 recordings, we were unable to obtain a satisfactory simple binomial model (hereafter called binomial model), a ratio similar to that reported in comparable studies (Koester and Johnston, 2005; Sáez and Friedlander, 2009). Failure to obtain a model for a connection was either as a result of the fitting algorithm being unable to compute an optimal solution or because the model failed on one or more of the rigorous statistical tests of adequacy. Three of our 180 recordings were rejected on the grounds of having experimental failure rates greatly exceeding that predicted by the model. The incorporation of the probability of conduction $\left(P_{\text {cond }}\right)$ as an additional parameter in the model of maximum likelihood describing the connections yielded adequate fits for these three datasets, with conduction probabilities of between 0.69 and 0.92 . These three connections were not analyzed further for this reason. 
A small number of the connections ( 6 of 50 for $\mathrm{L} 2 / 3$ to $\mathrm{L} 2 / 3$ and 3 of 12 for the L5 inputs) were fitted with a quantal model predicting $N=1$ (transmission mediated by a single release site). One possibility is that these connections were multi-release site connections with either a small quantal size and/or large quantal variance, combined with significant conduction failures. The mean quantal amplitude of $N=1$ connections ( $Q=344 \pm 208 \mu \mathrm{V}, n=6$ ) (see Fig. 4) was not significantly larger (for the $\mathrm{L} 2 / 3$ to $\mathrm{L} 2 / 3$ connections, $p>0.05$ ) than connections best fit by $N>1$ $(Q=282 \pm 143 \mu \mathrm{V}, n=44)$ (see Fig. 4), arguing against the multirelease site possibility. In addition, EPSPs showing failure rates exceeding that predicted by simple binomial models were rare. However, for $N=1$ connections, because there is only a single nonfailure peak in the histogram, the failure entry may include conduction failures in addition to synaptic failures, which would lead to an overestimate of the true synaptic failure rate. With respect to this issue, imaging techniques have been used to study axonal propagation in L2/3 pyramidal cells in brain slices, and conduction failures were only rarely observed (Koester and Sakmann, 2000).

Bootstrap resampling. Bootstrapping was used to estimate confidence intervals on fitted quantal parameters (Efron, 1979; Stricker et al., 1994). For each connection, we had $n$ trials of recorded EPSPs. We generated new sets of data referring to sets of EPSP amplitudes for each connection by randomly selecting, with replacement, $n$ EPSPs from the original set. Thus, some of the original EPSPs might appear more than once in the new set, whereas others might not appear at all. To avoid having several identical EPSPs in the new sets (which was correctly rejected by our battery of adequacy tests as being essentially impossible), we added a small amount of jitter to these resampled EPSPs. To each resampled EPSP, we added a random number drawn from a Gaussian, with a mean of 0 and an SD of one-quarter of the fitted noise SD (or five on the rare occasions in which one-quarter of the fitted noise SD was less than five). We then rounded the result to the nearest whole number to make all resampled EPSPs into integers, as they were in the original data (expressed as microvolts). This set of resampled EPSPs was then fitted in exactly the same manner as the original EPSPs were, and the resampled fit was tested for adequacy using the same selection of statistical tests that were applied to the original fit. If the resampled fit passed these tests, it was accepted as a valid resampled fit. The entire procedure was then repeated until 100 valid resampled fits had been acquired for each connection, giving 100 estimates of $Q, N$, and $P_{\mathrm{r}}$ for each connection. Sixtyeight percent confidence intervals derived from these resamples (or SEs) are shown in Figure 7 for $P_{\mathrm{r}}, Q$, and $N$ for the $\mathrm{L} 2 / 3$ to $\mathrm{L} 2 / 3$ connections and for $P_{\mathrm{r}}$ and $Q$ for the layer 5 inputs. Ninety-five percent confidence limits for $P_{\mathrm{r}}$ and $Q$ for the L2/3 to L2/3 connections are shown in supplemental Figure $2 b$ (available at www.jneurosci.org as supplemental material). For most connections, these confidence intervals were large, raising the question of whether correlations between these two variables can be trusted. To assess this, for each correlation investigated, we used bootstrap resampling to estimate confidence intervals for the correlation $r^{2}$ and the significance $p$. Referring to the $P_{\mathrm{r}}-Q$ relationship for the $\mathrm{L} 2 / 3$ to L2/3 connections ( $n=50$ pairs), for each connection, we had 100 resampled values for $P_{\mathrm{r}}$ and 100 resampled values for $Q$. We generated new scatter plots of $P_{\mathrm{r}}$ versus $Q$ by randomly picking one of these 100 data points for each of the connections in the scatter plot. In this way, potentially $100^{50}$ (or $10^{100}$ ) scatter plots could be generated. We generated a random subset of $10^{5}$ of these $10^{100}$ scatter plots. Four examples are shown in supplemental Figure $2 c$ (available at www.jneurosci.org as supplemental material). For each resampled scatter plot, we calculated the correlation between the resampled $P_{\mathrm{r}}$ and $Q$ and the associated $p$ value. We thus ended up with $10^{5}$ resampled values for $r^{2}$ and $p$. Distributions are shown in supplemental Figure $2 d$ (available at www.jneurosci.org as supplemental material). The resampled $r^{2}$ values were approximately normally distributed, with a mode a little lower than the $r^{2}$ for the original dataset. Thus, many of the resampled datasets had stronger correlations than that observed in the original dataset. The resampled values for the significance $p$ are the most critical in enabling us to assess the reliability of the original correlation. For all but 4 of 10,000 resampled scatter plots (i.e., $99.996 \%$ ), the $P_{\mathrm{r}} / Q$ correlation was significant at the 0.05 level. Thus, despite the large confidence intervals for individual points in the scatter plot, the overall correlation is extremely statistically robust. We
Table 1. Electronic parameters for the model cortical pyramidal neurons at different temperatures

\begin{tabular}{llllll}
\hline & Layer $2 / 3$ & & & Layer 5 \\
& Room $\left(26^{\circ} \mathrm{C}\right)$ & Body $\left(36^{\circ} \mathrm{C}\right)$ & & Room $\left(26^{\circ} \mathrm{C}\right)$ & Body $\left(36^{\circ} \mathrm{C}\right)$ \\
\hline$C_{\mathrm{m}}\left(\mu \mathrm{F} / \mathrm{cm}^{2}\right)$ & 0.94 & 0.94 & 1.0 & 1.0 \\
$R_{\mathrm{m}}\left(\mathrm{k} \Omega / \mathrm{cm}^{2}\right)$ & 37.4 & 21.9 & & 24.0 & 12.0 \\
$R_{\mathrm{i}}(\Omega / \mathrm{cm})$ & 155 & 140 & & 190 & 150 \\
$G_{\text {sh }}(\mathrm{nS})$ & 1.8 & 7.3 & 0 & 0 \\
\hline
\end{tabular}

can confidently reject the possibility that the original correlation $\left(r^{2}=\right.$ 0.36 ) was a chance occurrence. The same procedure was also used to estimate the reliability of other correlations tested in this study.

Histological procedures. After recording from pairs of neurons, slices were fixed overnight in $4 \%$ paraformaldehyde, resectioned at $100 \mu \mathrm{m}$, and reacted to visualize the biocytin as described previously (Trevelyan and Jack, 2002). Only pairs of cells that displayed no obvious truncation of dendritic or axonal profiles, indicative of damage during histological processing, were analyzed further. Drawings of labeled pairs of cells were made using a camera lucida and subsequently reconstructed (Trevelyan and Jack, 2002) . No correction for shrinkage was performed. Putative synaptic contacts (defined as zones in which a synaptic bouton and postsynaptic dendrite came into close apposition in the same focal plane) were identified and photographed using the $100 \times$ objective on a Nikon Axiophot microscope. The majority of contacts were on dendritic spines and not directly on dendritic shafts. For a subset of reconstructed pairs of neurons $(n=4)$, we were able to process the tissue through to electron microscopy to confirm the identity of synaptic contacts ( $n=8$ contacts). The area of contact was serially sectioned at $70 \mathrm{~nm}$ using a Leica ultramicrotome. The sections were collected on Formvar-coated grids and photographed using a Jeol 1010 transmission electron microscope. The electron micrograph images allowed serial reconstruction of the boutons; volumes were calculated from the area of the sections and their known thickness.

Modeling data from layer $2 / 3$ and layer 5 pyramids. Simulations of the distribution of synaptic profiles were obtained using anatomically accurate passive cable models of pyramidal cells from previously published studies [L2/3 (Trevelyan and Jack, 2002); L5 (Larkman et al., 1992)]. In these studies, biophysical parameters were derived by matching the experimentally recorded voltage response to a brief somatic current injection with the behavior of the model neuron to the same stimulus, yielding values at both room and physiological temperatures (Table 1). The models are available on request.

The synaptic simulations used a branching cable analytical solution with the synaptic current being simulated by the local injection of $0.1 \mathrm{pC}$ of charge $(Q)$ over a time course described by the sum of two exponentials (Major et al., 1994):

$$
i(t)=\frac{Q}{\tau_{\text {rise }}-\tau_{\text {decay }}}\left(e^{-t / \tau_{\text {rise }}}-e^{-t / \tau_{\text {decay }}}\right)
$$

with time constants $\tau_{\text {rise }}$ of $0.2 \mathrm{~ms}$ and $\tau_{\text {decay }}$ of $2.5 \mathrm{~ms}$. This synaptic current was simulated at every 10th dendritic spine to give a distribution profile for the entire excitatory input to the cell.

Statistical analysis. All comparisons between distributions of data were performed using two-sample $t$ tests. Regressions of data scatter plots were linear, although for amplitude/failure rate scatter plots, hyperbolic fits described the data distributions much more closely (Markram et al., 1997). All population means are given with SDs unless stated.

\section{Results}

\section{Synaptic strength and reliability of cortical synaptic connections}

To investigate the properties of synaptic connections between pyramidal neurons in rat visual cortex, we recorded EPSPs from synaptically coupled neurons (Fig. 1). Recordings were made between pairs of L2/3 neurons $(n=137$ ) (Fig. $1 a, b)$, between L2/3 
and L5 neurons $(n=20)$ (Fig. $1 c, d)$, and between pairs of layer 5 neurons $(n=23)$ (Fig. 1e,f).

For each connection, we calculated the mean EPSP amplitude (Fig. 2), the failure rate (a measure of the reliability of the connection) (Fig. 2), and the trial-to-trial variance in EPSP amplitude [measured as the CV (supplemental Fig. 3, available at www.jneurosci.org as supplemental material)]. The mean EPSP amplitude of L2/ $3-\mathrm{L} 2 / 3$ connections ranged from $42 \mu \mathrm{V}$ to $2.9 \mathrm{mV}$ (mean of $433 \pm 429 \mu \mathrm{V}, n=137$ ). Mean EPSP amplitudes of L5 to L5 connections were comparable (range of 121 $\mu \mathrm{V}$ to $2.1 \mathrm{mV}$, mean of $503 \pm 504 \mu \mathrm{V}, n=$ 23), whereas L $2 / 3$ to L5 connections were significantly weaker (mean of $237 \pm 259$ $\mu \mathrm{V}$, range of $22 \mu \mathrm{V}$ to $1.0 \mathrm{mV}, n=20$ ) (Fig. 2a). The mean failure rate of connections between $\mathrm{L} 2 / 3$ neurons and for $\mathrm{L} 2 / 3$ to $\mathrm{L} 5$ connections was similar $(0.25 \pm$ $0.18, n=137$ and $0.29 \pm 0.23, n=20$, respectively) (Fig. $2 b$ ). In contrast, L5 to L5 connections were more reliable, with a lower failure rate of $0.12 \pm 0.13(n=23)$ (Fig. 2b). Connections between different cortical layers have been shown previously to occupy different regions of parameter space in amplitude versus failure plots (Brémaud et al., 2007). Consistent with this, the trial-totrial variability of L5 to L5 connections (as measured by the CV) was significantly lower than either the L2/3 to L2/3 or L2/3 to L5 connections (supplemental Fig. $3 a$, available at www.jneurosci. org as supplemental material). For all connections, failure rate was negatively correlated with EPSP amplitude (Fig. 2c), demonstrating that strong connections (as determined by mean EPSP amplitude) were also the most reliable. The trial-to-trial variability in EPSP amplitude (measured as the CV) was also negatively correlated with mean EPSP amplitude for all connections (supplemental Fig. 3b, available at www.jneurosci.org as supplemental material). In addition, there was a strong positive correlation between failure rate and $\mathrm{CV}$ values for $\mathrm{L} 2 / 3$ to $\mathrm{L} 2 / 3$ connections and inputs onto L5 neurons (supplemental Fig. $3 c, d$, available at www.jneurosci.org as supplemental material).

\section{Rise time as an indicator of synapse location}

EPSP rise time can be used as an indicator of the location of the synaptic input on the dendritic tree of the postsynaptic neuron (Magee and Cook, 2000). To investigate this, we measured the $10-90 \%$ rise time of the mean EPSP response for each of our connected pairs (Fig. 3) (supplemental Fig. 3e, available at www. jneurosci.org as supplemental material). Rise times of EPSPs recorded between pairs of L2/3 neurons ranged from 1.4 to $9.8 \mathrm{~ms}$ (mean of $3.4 \pm 1.3 \mathrm{~ms}, n=137$ ) (Fig. $3 a$ ) (supplemental Figs. 7, 8 , available at www.jneurosci.org as supplemental material).

EPSPs recorded from L5 neurons had on average slower rise times than L2/3 pairs, for both L5 inputs (mean rise time of $4.3 \pm$ $1.0 \mathrm{~ms}$, range of $2.5-6.1 \mathrm{~ms}, n=23$ ) and particularly L2/3 inputs (mean rise time of $5.2 \pm 2.7 \mathrm{~ms}$, range of $1.7-11.8 \mathrm{~ms}, n=20$ ) (Fig. 3b) (supplemental Fig. 3e, available at www.jneurosci.org as supplemental material). To investigate the relationship between rise time and dendritic location for both L2/3 and L5 neurons,
C

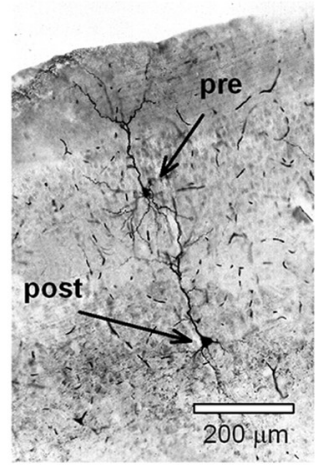

e

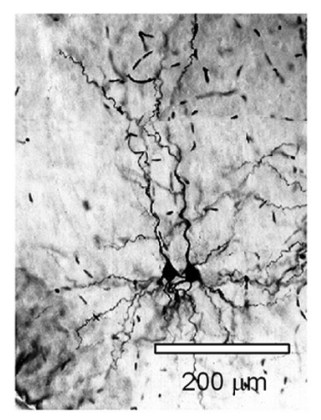

d

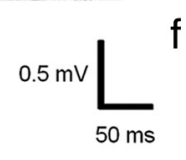

f

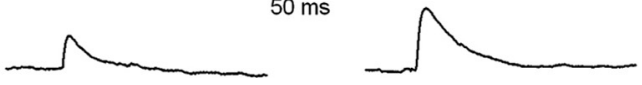

Figure 1. Recordings from synaptically connected pyramidal neurons in the cortex. $\boldsymbol{a}$, Photomicrograph of a pair of $L 2 / 3$ tissue was subsequently processed by conventional methods to enable visualization of recorded neurons $\boldsymbol{b}$, Recordings made from a d a d a postsynaptic neuron (top). c, Photomicrograph of otential generated in a presynaptic (L2/3) neuron. $\boldsymbol{e}$, Photomicrograph of a pair of $L 5$ pyramidal neurons that are synaptically $\mathrm{L} 5$ neuron evoked by an action potential generated in another $\mathrm{L} 5$ neuron.
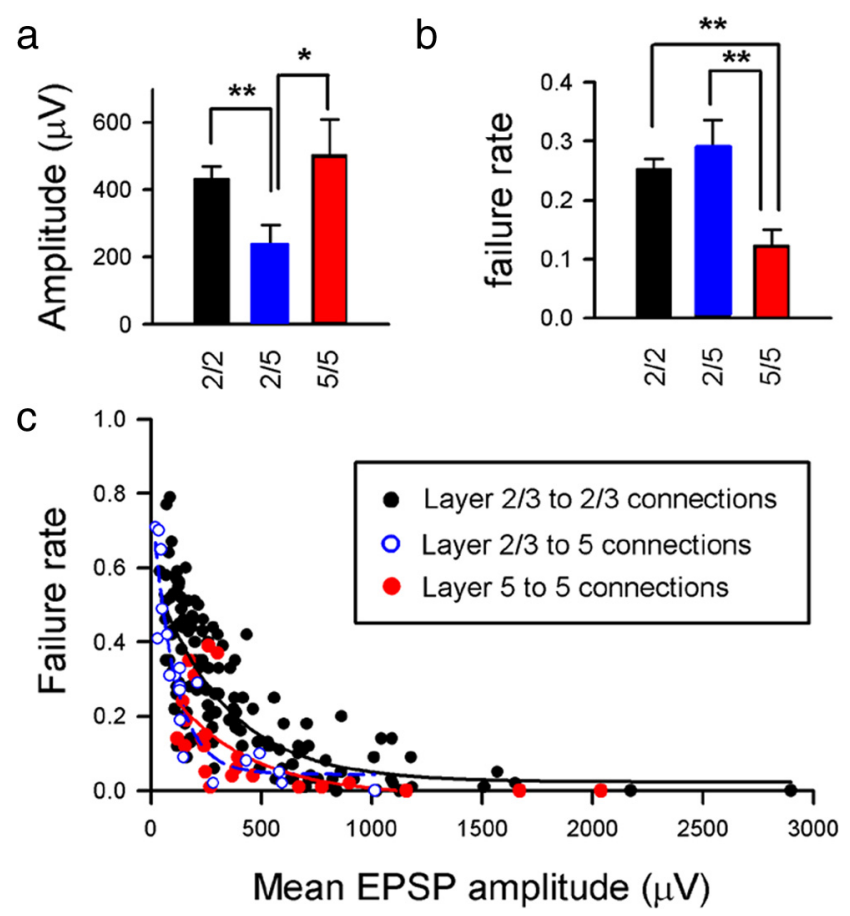

Figure 2. Amplitude and reliability of EPSPs recorded in layer $2 / 3$ and layer 5 pyramidal neurons. Comparisons of mean amplitudes $(\boldsymbol{a})$ and mean failure rates $(\boldsymbol{b})$ for populations of $L 2 / 3$ to L2/3 connections (black), L2/3 to L5 connections (blue), and L5 to L5 connections (red). ${ }^{*} p<0.05,{ }^{* *} p<0.01$, for paired comparisons. $c$, A scatter plot of mean EPSP amplitude plotted against transmission failure rate shows a similar correlation for $\mathrm{L} 2 / 3$ connections (black circles and hyperbolic fit line; $r^{2}=0.62, p<0.001$ ) to L2/3 inputs to L 5 cells (blue/white circles and blue hyperbolic fit line; $r^{2}=0.85, p<0.001$ ) and $L 5$ to $L 5$ connections (red circles and hyperbolic fit line; $r^{2}=0.40, p<0.01$ ). 
a

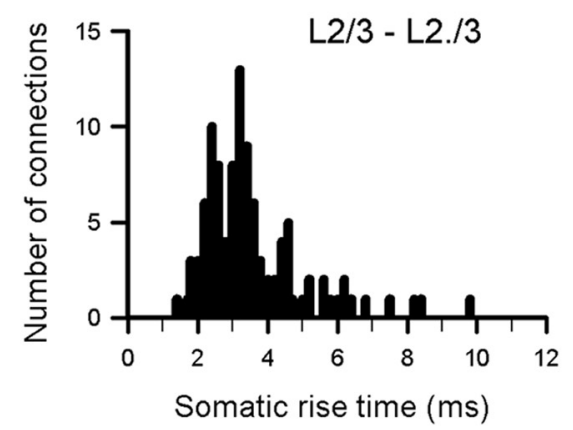

C

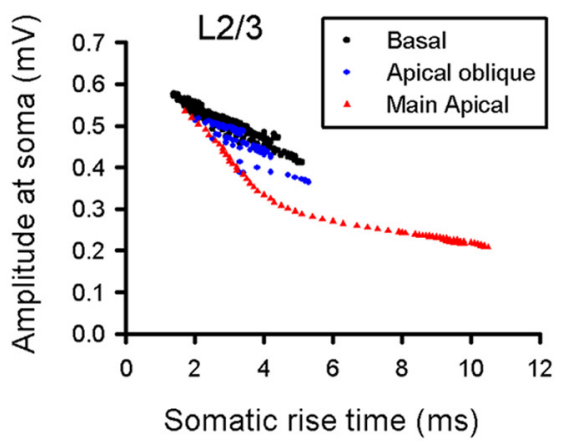

b

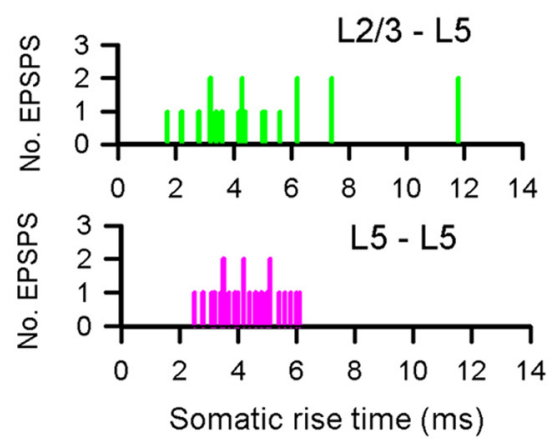

d

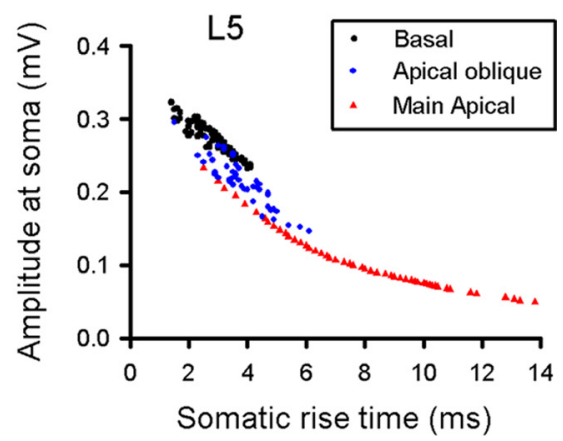

Figure 3. Rise time as an indicator of dendritic location of EPSP. Distribution of experimental $10-90 \%$ EPSP rise times for recordings made from pairs of $L 2 / 3$ pyramidal neurons $(\boldsymbol{a}), L 2 / 3$ to $L 5$ pairs $(\boldsymbol{b}$, top), and $L 5$ to $L 5$ connections $(\boldsymbol{b}$, bottom) at room temperature. The effect of dendritic location on somatic EPSP amplitude and rise time was investigated using a representative $L 2 / 3$ (c) and $\mathrm{L} 5(\boldsymbol{d})$ model neuron. Simulated EPSPs were generated using a brief injection of charge $(0.1 \mathrm{pC})$ into every 50 th spine across the entire dendritic arbor of the model neurons.
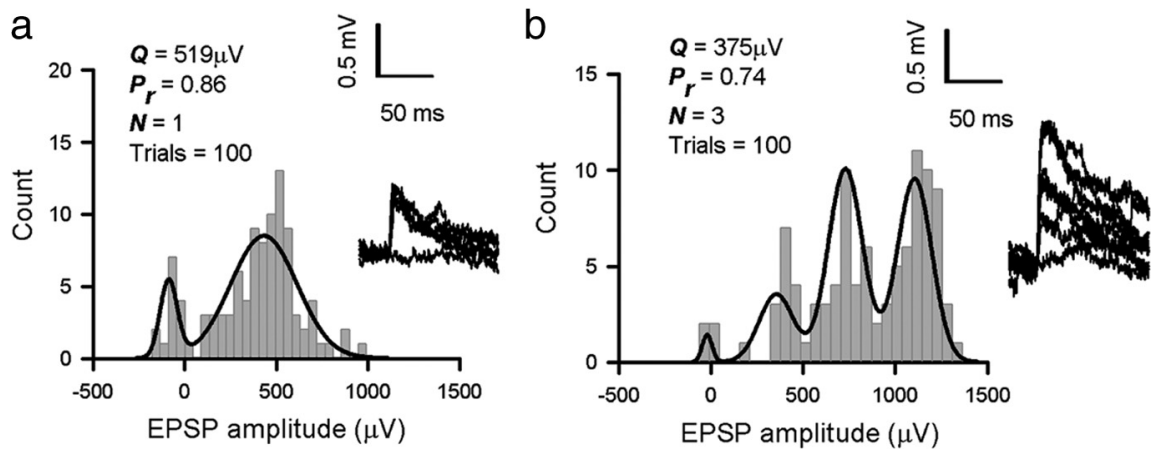

Figure 4. Quantal analysis of layer $2 / 3$ to layer $2 / 3$ connections. $\boldsymbol{a}$, Amplitude frequency histogram of a putative single release site connection, best-fit model $\left(N=1, Q=519 \mu \mathrm{V}, P_{\mathrm{r}}=0.86\right)$; inset, overlaid EPSP raw traces with direct current offset subtracted. $\boldsymbol{b}$, Amplitude frequency histogram of a multi-release site connection, best-fit model $\left(N=3, Q=375 \mu \mathrm{V}, P_{r}=0.74\right)$; inset, overlaid EPSP raw traces with direct current offset subtracted, drawn to same scale as $\boldsymbol{a}$. Mean values of quantal amplitude for putative single release site L2/3 to L2/3 connections $(n=6, Q=344 \mu \mathrm{V})$ and multi-release site L2/3 to L2/3 connections ( $n=$ $44, Q=282 \mu \mathrm{V}$ ) were not different (comparison by paired $t$ test, $p>0.05$, not significant). Two of five $L 2 / 3$ to $L 5$ connections were single release site connections, as were one of the seven $L 5$ to $L 5$ connections.

we used a passive cable model of representative L2/3 and L5 pyramidal neurons from previous studies (Larkman et al., 1992; Trevelyan and Jack, 2002). Simulated synaptic currents of identical size were injected at every 10th spine across the entire dendritic tree of each model neuron and the EPSP waveform was calculated for each simulated EPSP when recorded at the soma. The rise time of each simulated EPSP was then plotted as a function of its peak somatic amplitude (Fig. 3c,d). For L2/3 neurons, the range of experimental rise times is consistent with anatomical studies, which have shown that the large majority of excitatory inputs onto layer $2 / 3$ neurons are made onto basal or apical oblique dendrites (Larkman, 1991). This also holds for the majority of inputs onto L5 cells, particularly for inputs from other L5 cells (Larkman, 1991).

Both anatomical studies (Markram et al., 1997; Feldmeyer et al., 2006) and previous quantal studies (Hardingham et al., 2006, 2007; Brémaud et al., 2007; Sáez and Friedlander, 2009) support the idea that connections made between cortical pyramidal neurons are commonly mediated via more than one functional or anatomical release site. For a given synaptic current, the precise location of the synaptic contact on the dendritic tree determines the peak somatic amplitude it evokes. For L2/3 neurons, the effect of dendritic filtering in basal and proximal oblique dendrites is relatively small $(<30 \%)$ (supplemental Fig. 4, available at www.jneurosci. org as supplemental material), indicating that synaptic efficacy (as recorded at the soma relative to a hypothetical somatic synaptic input) is relatively high. A result of this is that identical synaptic currents distributed over the basal and apical oblique dendritic trees (which represent a large proportion of the excitatory synaptic inputs into these cells) are likely to generate EPSPs of similar amplitude when recorded at the soma. Therefore, the effect of intersite quantal variability brought about by differential dendritic location is likely to be small, and this fact may therefore make recordings amenable to quantal analysis.

\section{Extracting quantal parameters for cortical synapses}

To quantify the cortical synaptic circuitry in more detail, we used quantal analysis techniques on stable periods of recorded connections (Larkman et al., 1997; Hardingham et al., 2006, 2007). EPSP amplitude distributions for each connection (reflecting the trial-to-trial fluctuations in EPSP amplitude) were fitted with a simple binomial quantal model of transmitter release (Hardingham and Fox, 2006; Hardingham et al., 2007). In such a model, $Q$ represents the amplitude of the postsynaptic EPSP generated by the release of neurotransmitter at a single release site (as recorded at the soma), $N$ is the number of release sites at which release of neurotransmitter can occur, and $P_{\mathrm{r}}$ is the probability that a vesicle of neurotransmitter is released at each site in response to stimulation. EPSP amplitude distributions from 50 connected pairs of L2/3 neurons (from a total of 137) could be described by a simple binomial model (Fig. 4a,b). The majority of these connections (44 of 50) were fitted with a model predicting $N>1$ (i.e., connections mediated by more than one release site) (Fig. $4 b$ ). 
a
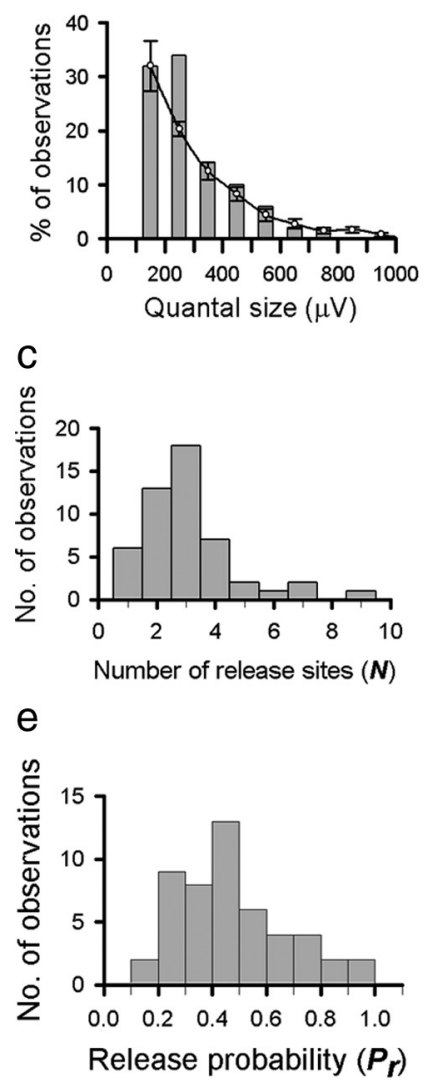

b

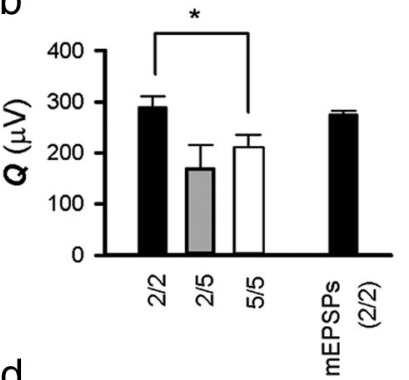

d

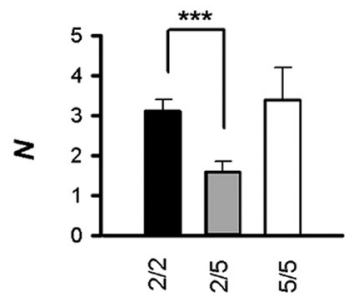

$f$

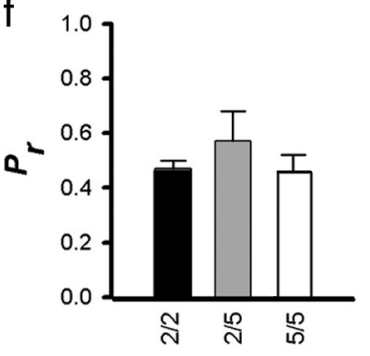

Figure 5. Synaptic parameters derived from quantal analysis. $\boldsymbol{a}$, The distribution of quantal amplitudes derived from model fits (bars; mean amplitude of $289 \pm 151 \mu \mathrm{V}$ ) is consistent $(p>0.05)$ with the relative distribution of mEPSP amplitudes from a population of four $L 2 / 3$ neurons (lines with error bars; 500 recorded from each neuron, mean amplitude of $275 \pm 163$ $\mu \mathrm{V})$. $\boldsymbol{b}$, Mean values of quantal size for $L 2 / 3$ to $L 2 / 3$ connections (black), $L 2 / 3$ to $L 5$ connections (gray), and L5 to L5 connections (white). The black bar on the right is the mean amplitude of mEPSPs recorded from $L 2 / 3$ neurons. $c$, The distribution of functional release sites $(N)$ for $L 2 / 3$ connections (mean of $3.1 \pm 1.6)$. $\boldsymbol{d}$, Mean values of $N$ (number of functional release sites) for $L 2 / 3$ to $L 2 / 3$ connections (black), layer $L 2 / 3$ to $L 5$ connections (gray), and L5 to $L 5$ connections (white). $\boldsymbol{e}$, The distribution of $P_{\mathrm{r}}$ for $L 2 / 3$ connections (mean of $0.47 \pm 0.20$ ). $\boldsymbol{f}$, Mean values of $P_{r}$ for $L 2 / 3$ to $L 2 / 3$ connections (black), $L 2 / 3$ to $L 5$ connections (gray), and $L 5$ to $L 5$ connections (white). ${ }^{*} p<0.05,{ }^{* * *} p<0.001$ for paired comparisons.

However, we found that the mean quantal amplitude of connections best fit by a single release site $(N=1, Q=344 \pm 208$ $\mu \mathrm{V}, n=6$ ) (Fig. $4 c$; see also $a$ ) was not significantly different $(t$ test, $p=0.48$ ) from the quantal amplitude of connections best fit by more than one release site $(N=3.34 \pm 1.52, Q=282 \pm$ $143 \mu \mathrm{V}, n=44$ ) (Fig. 4c).

There appeared to be little selection bias evident in connections yielding quantal models compared with the population as a whole with respect to mean amplitude, failure rate, or EPSP $10-$ $90 \%$ rise time (supplemental Fig. 5, available at www.jneurosci. org as supplemental material). Estimates of $Q$ for the L2/3 connections that we were able to fit a model to ranged from 104 to $782 \mu \mathrm{V}$, with a mean of $289 \pm 151 \mu \mathrm{V}(n=50)$ (Fig. $5 a, b)$. Estimates of quantal size for both L5 to L5 and L2/3 to L5 connections (Fig. $5 b$ ) were smaller than L2/3 to L2/3 (L5 to L5: $211 \pm$ $65 \mu \mathrm{V}$, range of $106-302 \mu \mathrm{V}, n=7 ; \mathrm{L} 2 / 3$ to $\mathrm{L} 5: 170 \pm 104 \mu \mathrm{V}$, range of $82-349 \mu \mathrm{V}, n=5)$. All connections had the statistical reliability of their peaks tested using an autocorrelation-based technique (see Materials and Methods) (Stratford et al., 1997).

To obtain an independent estimate of quantal size from the

quantal analysis, we recorded mEPSPs from a separate population of layer L2/3 neurons in the presence of TTX and PTX (which represent EPSPs from single release sites). The distribution of mEPSP amplitudes (mean of $275 \pm 163 \mu \mathrm{V}, n=2000$ amplitude measures collected from 4 neurons) was also similar to that of the quantal amplitudes derived from quantal analysis of paired recordings (two-sample $t$ test, $p=0.56$ ) (Fig. 5a). The $10-90 \%$ rise time of mEPSPs (mean of $3.50 \pm 1.67 \mathrm{~ms}$ ) was comparable with the $10-90 \%$ rise time of the whole population of evoked EPSPs recorded in L2/3 neurons $(3.40 \pm 1.35 \mathrm{~ms}, n=$ $137, p>0.05$ ) (supplemental Fig. 5b, available at www.jneurosci. org as supplemental material) and the subset of evoked PSPs subjected to a quantal analysis $(3.20 \pm 1.26 \mathrm{~ms}, n=50, p>0.05)$. As well as assigning values for $N, P_{\mathrm{r}}$, and $Q$, the model incorporated a parameter to account for quantal variance $(\mathrm{QV})$. Quantal variance can result from two sources: type 1 or intrasite quantal variance (the trial-to-trial fluctuation in postsynaptic response at a single release site) or type 2 quantal variance (variability in quantal size between release sites) (Wahl et al., 1995). The presence of type 1 quantal variance will be additive, thereby increasing the width of quantal peaks toward the right of the amplitude histogram, leading to the smearing of quantal peaks, especially in connections with a small quantal amplitude or a large number of release sites. In contrast, type 2 quantal variance will tend to sharpen peaks toward the right of the amplitude histogram (Wahl et al., 1995). To accommodate these two possibilities, the optimizer was allowed to fit the data with either type 1 quantal variance alone or type 1 in combination with type 2 (implemented as flat or equal quantal variance across all amplitude peaks). Quantal variance was strongly correlated with quantal size for $L 2 / 3$ to L2/3 connections $\left(r^{2}=0.70, p<0.001\right)$ (supplemental Fig. $5 e$, available at www.jneurosci.org as supplemental material). For the $2 / 3$ to $2 / 3$ connections, $40 \%$ were best fit with type 1 quantal variance, and $60 \%$ were best fit with flat quantal variance, suggesting that some degree of intersite quantal variance was present at the connections, although values of $Q, P_{r}, N$, and $Q_{\text {sig }}$ were not significantly different if models were constrained to either type 1 or flat QV (all $p>0.05$ ). Values of $Q_{\text {sig }}$ constrained to type 1 variance were also strongly correlated with values of $Q_{\text {sig }}$ for the same connection when constrained to flat quantal variance (data not shown; $\left.r^{2}=0.64, p<0.001\right)$. Quantal variance expressed as a coefficient of variance ranged from 0 to $41 \%$, with a mean of $17 \pm 10 \%(n=50,16 \pm 10 \%$ fitted with just type 1 quantal variance, $18 \pm 11 \%$ fitted with just flat quantal variance). The quantal variance was substantially higher than this for connections that failed on one or more of the quantal analysis tests (mean QV of $43 \pm 39 \%, n=87$ ).

Determining the number of functional release sites per connection $(N)$ and subsequently $P_{\mathrm{r}}$ is more problematic than deriving values for $Q$ (which is visually evident from examining the peak spacing in the amplitude distribution) and statistically validated by our autocorrelation-based method). A more reliable measure of synaptic strength is $m$, the mean number of quanta released per trial, a measure of total presynaptic strength. The problem of separating out $m$ into $P_{\mathrm{r}}$ and $N$ is especially apparent for low $P_{\mathrm{r}}$ connections in which release sites are rarely all active at the same time (Bekkers and Stevens, 1995).

Estimates for the number of release sites $(N)$ between connected pairs of L2/3 neurons ranged from 1 to 9 , with a mean of $3.1 \pm 1.6(n=50)$ (Fig. $5 c, d)$. Estimates for $N$ for L5 inputs ranged from 1 to 2 for L2/3 to L5 connections ( $n=5$, mean of $1.6 \pm 0.5)$ (Fig. $5 d$ ) and from 1 to 7 for L5 to L5 connections $(n=$ 7 , mean of $3.4 \pm 2.2$ ) (Fig. $5 d$ ). With respect to quantal size, we 
a

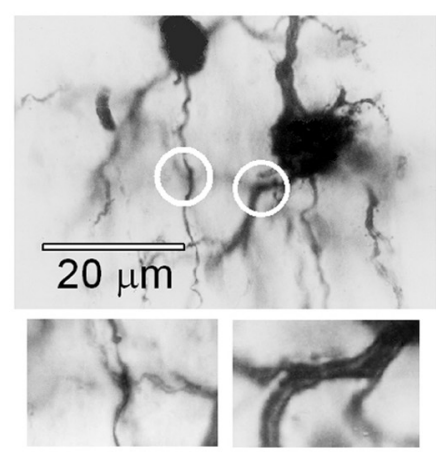

C

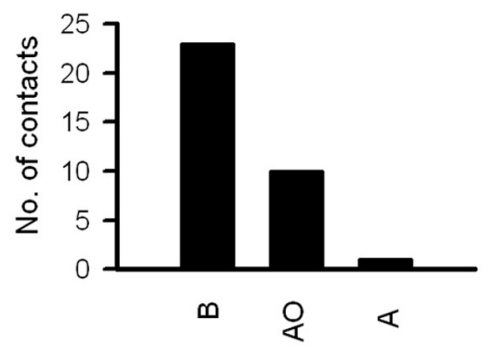

e

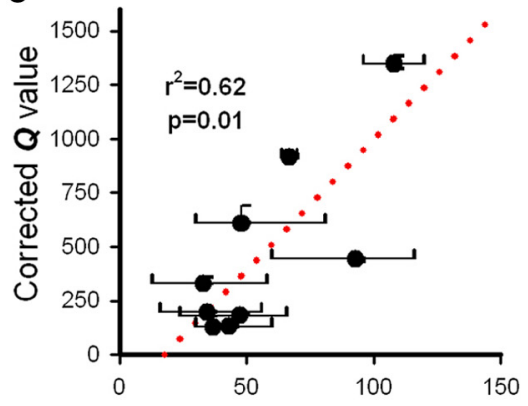

Mean length of contact to soma $(\mu \mathrm{m})$

b

d

f

g
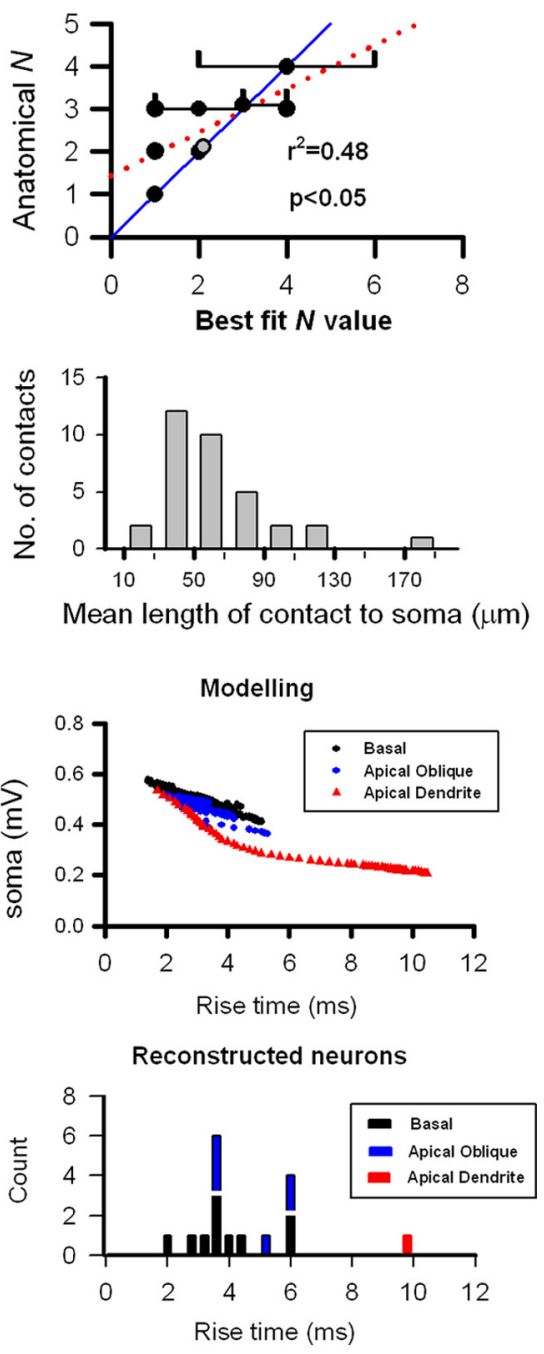

Figure 6. Number of functional release sites for $L 2 / 3$ to $L 2 / 3$ connections correlates with number of putative anatomical contacts. $\boldsymbol{a}$, A photomicrograph showing the two points of contact (circled) between the presynaptic axon and postsynaptic dendrite of a synaptically connected pair of $\mathrm{L} 2 / 3$ neurons. The two inset boxes show the contact sites at higher magnification (at slightly different focal planes to the main image). $\boldsymbol{b}$, Model fit values of $N$ correlate with the number of anatomical contact points between presynaptic axons and postsynaptic dendrites (linear regression is red dotted line; $r^{2}=0.48, p<0.05$ ). Confidence limits for model fits of $N$ overlap anatomical $N$ values in the majority of cases (on the blue unity line), whereas five of the nine points were exact matches between functional $N$ and anatomical $N$. Note that there are two points on the graph at coordinates $(2,2)$. One is a black symbol, and the other one is gray (slightly offset from black). $c$, The distribution of contact sites for the 13 reconstructed pairs of neurons are primarily on basal dendrites $(B ; 23)$ and apical obliques $(A 0 ; 10)$, with only one contact site $(1)$ on the main apical dendrite (A).d, Putative synaptic contact points are mostly proximal to the soma at a mean distance of $62 \pm 38 \mu \mathrm{m}$. $\boldsymbol{e}$, Mean distance of synaptic contacts from the postsynaptic soma for a connection (bars represent ranges) is correlated with corrected (synaptic) $Q$ value $\left(r^{2}=0.62, p<0.01\right)$; distance was not correlated with uncorrected (somatic) $Q$ value (data not shown; $r^{2}=$ $0.24, p>0.05$ ). For derivation of corrected $Q$ values, see supplemental Figure 6 (available at www.jneurosci.org as supplemental material). The mean EPSP rise time for each connected pair of neurons that was subsequently anatomically reconstructed, color coded by the dendritic location of putative synaptic contacts, is shown in $\boldsymbol{g}$. Four connections had putative contacts on both basal (black) and apical oblique (blue, separated by a white line) dendrites. This correlates well with modeling data $(\boldsymbol{f})$ shown previously in Figure $3 c$.

were able to obtain an alternative independent measure by recording mEPSPs. Obtaining an independent estimate for $N$ and $P_{\mathrm{r}}$ is more difficult. However, for a subset of $\mathrm{L} 2 / 3$ to $\mathrm{L} 2 / 3$ connections $(n=13)$, we were able to make anatomical reconstructions of the recorded neurons after filling with biocytin to allow us to investigate putative "anatomical $N$ " (Fig. 6a).

\section{Reconstructions of connected pairs of layer $2 / 3$ pyramidal neurons}

From light microscope observations, we were able to identify possible sites of contact between presynaptic axon varicosities and postsynaptic dendritic spines (Fig. $6 a)$. The mean number of putative contacts per connected pair of neurons $(N)$ was $2.6 \pm 0.9(n=13)$, with a range of 1 to 4. For 9 of these 13 connections, quantal analysis was able to predict the number of functional release sites that these connections were mediated by, and values of functional $N$ were correlated with the number of putative synaptic contacts identified from anatomical reconstructions $\left(n=9, r^{2}=0.48, p<0.05\right)$ (Fig. $\left.6 b\right)$. Five of these nine connections had the same values for best-fit binomial model $N$ and anatomical $N$, and the best-fit linear regression was close to the diagonal (Fig. $6 b)$. The majority of contacts were on basal dendrites (23 contacts, 68\%) and apical oblique dendrites (10 contacts, $29 \%$ ); only one contact (3\%) was found on the proximal apical dendrite (Fig. $6 c$ ). The majority of the putative synaptic contacts were made at dendritic locations relatively proximal to the cell body of the postsynaptic neuron (mean path length of $62 \pm 38 \mu \mathrm{m}, n=34$ ) (Fig. $6 d$ ). For these connections, quantal size corrected for dendritic location [using EPSP rise time (see legend to supplemental Fig. 6, available at www.jneurosci.org as supplemental material)] was positively correlated with the average distance of the synapse to soma $\left(r^{2}=0.62, p<0.01\right)$ (Fig. 6e), although this correlation did not hold for quantal size uncorrected for dendritic location $\left(r^{2}=0.24, p=0.16\right.$; data not shown). The dendritic locations of the putative synaptic contacts determined anatomically were also consistent with predictions from the modeling data based on the EPSP rise time (Fig. $6 f, g$ ). For a small subset of recordings, bouton volume (measured from serial electron microscope sections) could be calculated and was correlated with somatic $Q$ [or corrected $Q$ (data not shown), $r^{2}=0.82$, $p<0.05, n=4$ connections, 8 boutons].

Additional supporting evidence for goodness of fit for $N$ is provided by a number of L2/3 to L2/3 connections in which we were able to fit periods of data recorded at both $23-26^{\circ} \mathrm{C}$ and $36^{\circ} \mathrm{C}$ ( $n=5$; data not shown). For each of these connections, the model returned an identical value for the number of release sites from the $23-26^{\circ} \mathrm{C}$ and $36^{\circ} \mathrm{C}$ data, with a similar $Q$, but a significantly higher $P_{\mathrm{r}}$ at $36^{\circ} \mathrm{C}(n=5, p<0.05$; data not shown) (Hardingham and Larkman, 1998).

\section{Relationships between quantal parameters}

Estimates for the mean $P_{\mathrm{r}}$ for each connection ranged from 0.12 to 0.91 for L2/3 to L2/3 connections (mean of $0.47 \pm 0.20, n=$ 50 ) (Fig. $5 e$ e). Similar estimates were obtained from L $2 / 3$ to $\mathrm{L} 5$ and L5 to L 5 connections $(0.57 \pm 0.22, n=5$ and $0.46 \pm 0.21, n=7$, 
respectively) (Fig. 5f). There was a positive correlation between release probability and quantal size for both the L2/3 to L2/3 connections $\left(r^{2}=0.37, p<0.001\right)$ (Fig. 7a) and for both classes of input onto L5 neurons $\left(r^{2}=0.51, p<0.01\right)$ (Fig. $\left.7 b\right)$. Bootstrap resampling was used (as detailed in Materials and Methods) to produce SEs (68\% confidence intervals) for our estimates of $N, P_{\mathrm{r}}$, and $Q$, derived from the fitted binomial model (Efron, 1979; Stricker et al., 1994). Ninety-five percent confidence intervals for this plot are given in supplemental Figure 2 (available at www.jneurosci.org as supplemental material). To quantify the effect of the confidence limits on the $P_{\mathrm{r}}-Q$ correlation, quantal parameters for each connection were randomly selected from the resampled datasets, and correlations between $P_{\mathrm{r}}$ and $Q$ were recalculated. Virtually all of the resultant resampled correlations were significant ( $>99.9 \%$ for the L2/3 to L2/3 connections) (supplemental Fig. 2, available at www.jneurosci.org as supplemental material), suggesting that the correlation is robust and not simply an artifact of sampling. For the L2/3 to L2/3 connections, the number of release sites $(N)$ was also negatively correlated with $P_{\mathrm{r}}\left(r^{2}=0.36, p<0.001\right)$ (Fig. $7 c$ ). However, there was no correlation between quantal size and number of release sites for the $\mathrm{L} 2 / 3$ to L2/3 connections $\left(r^{2}=0.05, p>0.05\right.$; data not shown).

We were interested to see which of the quantal parameters were responsible for the 70 -fold range in mean amplitude observed between individual connections (Fig. 8). For L2/3 to L2/3 connections, mean EPSP amplitude was correlated with both $Q$ $\left(r^{2}=0.64, p<0.001\right)$ (Fig. 8a) and $m$, the mean number of quanta released per trial $\left(=N^{*} P_{\mathrm{r}}, r^{2}=0.51, p<0.001\right)$ (Fig. $8 c$ ). These correlations also existed for inputs onto L 5 cells $\left[r^{2}=0.37\right.$, $p<0.05$ (Fig. 8b); $r^{2}=0.79, p<0.001$ (Fig. $8 d$ )], suggesting that both presynaptic and postsynaptic factors contribute to synaptic efficacy in L2/3 and L5 cortex. From Figure $8, e$ and $f$, it is clear that for $2 / 3$ to $2 / 3$ connections, $P_{\mathrm{r}}$ and not the number of release sites $(N)$ is the key determinant in the correlation between mean EPSP amplitude and $m$ [Fig. 8, compare $e\left(r^{2}=0.34\right.$ for $\left.P_{\mathrm{r}}\right)$ with $f\left(r^{2}=0.01\right.$ for $\left.\left.N\right)\right]$. However, for layer 5 connections, $N$ and not $P_{\mathrm{r}}$ was significantly correlated with connection strength (data not shown).

There was no significant correlation between either mean EPSP amplitude and EPSP rise time or $Q$ and EPSP rise time for both L2/3 to L2/3 connections or inputs onto L5 cells (all $p>$ 0.05; data not shown). From modeling studies, it was clear that the dendritic location of synapses can influence both the rise time and the relative attenuation of inputs through dendritic filtering (Stratford et al., 1989; Trevelyan and Jack, 2002). To make some correction for possible attenuation, we used EPSP rise time as an indicator of probable dendritic location and applied a correction factor determined via models of the neurons (supplemental Fig. 6, available at www.jneurosci.org as supplemental material). After correction, both mean EPSP amplitude and quantal amplitude were significantly correlated with rise time for both $2 / 3$ to $2 / 3$ connections and layer 5 inputs (data not shown; all $p<0.05$ ).
However, correction of $Q$ for dendritic attenuation did not significantly improve the $P_{\mathrm{r}} / Q$ correlations $\left(r^{2}\right.$ values of 0.37 for the $2 / 3$ connections compared with 0.36 for the uncorrected data, and 0.53 for the layer 5 inputs compared with 0.51 for the uncorrected data) (data not shown) (refer to Fig. 7).

\section{Discussion}

This study sought to investigate the relationship between presynaptic and postsynaptic efficacy in developing cortical synapses, using electrophysiology and quantal analysis. As a result of our analysis, which assumed that synaptic release could be approximated by a single binomial model, we demonstrate a positive correlation between $P_{\mathrm{r}}$ and $Q$ at excitatory synapses between $\mathrm{L} 2 / 3$ pyramidal neurons and for excitatory inputs onto L5 pyramids from L2/3 and L5 pyramidal neurons.

\section{Low quantal variance is necessary for successful quantal analysis}

We were able to fit an adequate simple binomial model to approximately one-third of our dataset. Failure to fit a quantal model is primarily a result of an inability to discern clear quantal peaks in amplitude frequency histograms, which in the case of connections mediated by more than one release site may arise from quantal amplitudes varying considerably between release sites (type 2 quantal variance). Nonstationarity of quantal size over time (Larkman et al., 1997), poor signal-to-noise level, or large within-release site (type 1) quantal variance will also effect the likelihood of generating peaky histograms.

Under conditions of receptor saturation, type 1 quantal variance is primarily a result of to the stochastic nature of channel opening (Faber et al., 1992; Bannister et al., 2002) but can be considerably higher if transmitter fails to saturate postsynaptic receptors, making the quantal amplitude sensitive to peak concentration of glutamate within the synaptic cleft (McAllister and 

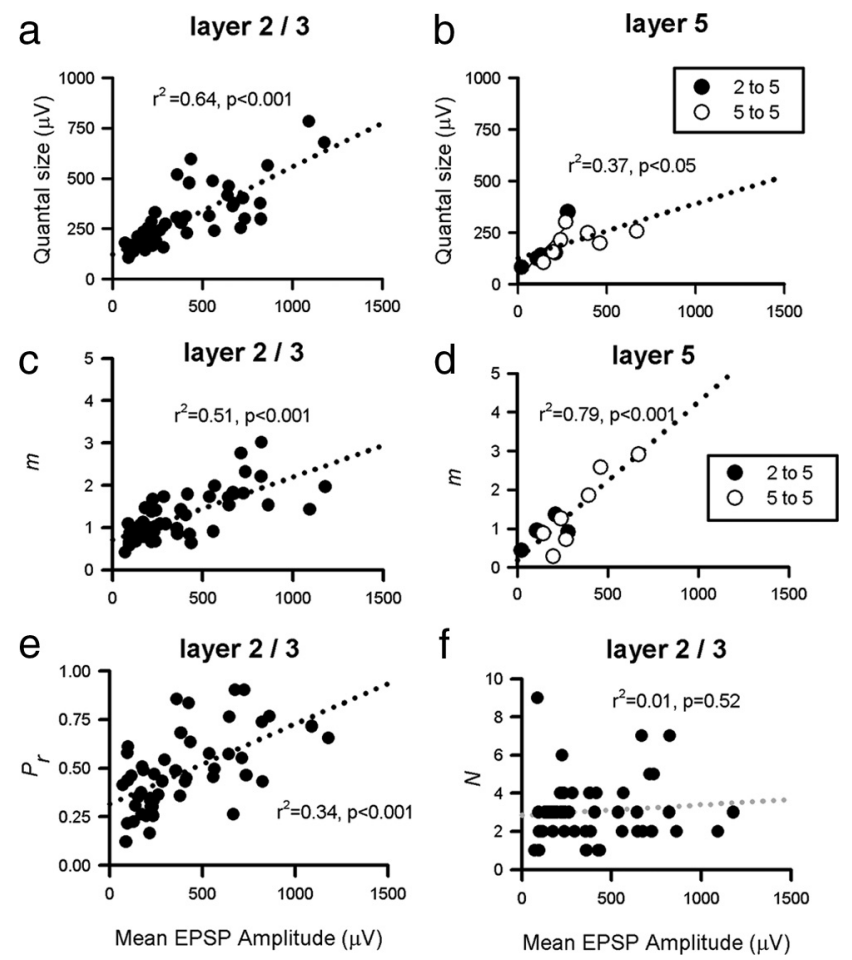

Figure 8. Correlation between EPSP amplitude and presynaptic/postsynaptic efficacy. Correlation between mean somatic EPSP amplitude and somatic $Q$ for $L 2 / 3$ to $L 2 / 3$ connections $\left(\boldsymbol{a} ; n=50, r^{2}=0.64, p<0.001\right)$ and inputs to $L 5\left(\boldsymbol{b} ; n=12, r^{2}=0.37, p<0.05\right)$. Correlation between mean EPSP amplitude and quantal content $(m)$, a measure of presynaptic strength, for $\mathrm{L} 2 / 3$ to $\mathrm{L} 2 / 3$ connections $\left(\boldsymbol{c} ; r^{2}=0.51, p<0.001\right)$ and inputs to layer $5\left(\boldsymbol{d} ; r^{2}=\right.$ $0.79, p<0.001$ ). The correlation in $c$ for $L 2 / 3$ to $L 2 / 3$ pairs can be shown to be primarily attributable to release probability being strongly correlated with mean amplitude $\left(\boldsymbol{e} ; r^{2}=\right.$ $0.34, p<0.001)$ with number of release sites uncorrelated with EPSP amplitude $\left(\boldsymbol{f} ; r^{2}=0.01\right.$, $p>0.05)$. Dotted lines represent linear fits.

Stevens, 2000). An observation worth mentioning is that the type I quantal variance correlates with quantal size (supplemental Fig. $5 e$, available at www.jneurosci.org as supplemental material), implying that there is receptor saturation with small quanta (small number of receptors) and progressively less saturation as the number of postsynaptic receptors increases. This may possibly be an artifact of the physical dimensions of the synapses.

Large quantal variance has been reported in neonatal animals [postnatal day 5 (P5) to P12 (Hanse and Gustafsson, 2001) or in cultured slices (Liu et al., 1999)]. At the mossy fiber to granule cell synapse in rat cerebellum, quantal variance falls between P11P15 and P40-P57 (CVs of 34 and 17\%, respectively) (Wall and Usowicz, 1998), suggesting that large quantal variance may be a feature of immature synapses. Given the age of animals that were used in our study (P19-P27), it is likely that our recordings represent some intermediary developmental stage, perhaps closer to a mature than an immature state for those EPSPs we could fit a model to because our mean CV of quantal variance was also $17 \%$.

Intersite (type 2) quantal variance may result from either differential filtering of synaptic currents located on different parts of the dendritic tree or from different quantal currents at each release site. The majority of excitatory inputs onto L2/3 and L5 neurons are on basal and apical oblique dendrites, which are electrotonically compact (Larkman et al., 1992; Markram et al., 1997; Trevelyan and Jack, 2002; Feldmeyer et al., 2006). Synaptic currents distributed over these dendritic trees generate EPSPs of similar amplitude at the soma (Nevian et al., 2007). Therefore, the effect of intersite quantal variability attributable to dendritic location is likely to be small. Consistent with this, there was no significant correlation between EPSP rise time and somatic $Q$ (supplemental Fig. 7, available at www.jneurosci.org as supplemental material) nor between somatic $Q$ and mean dendritic distance of the synapse from the soma (Fig. 6, legend), consistent with previous studies in L5 cortical neurons (Markram et al., 1997). After corrections for likely dendritic filtering, $Q_{\text {corr }}$ showed a significant correlation with EPSP rise time (supplemental Fig. 7, available at www.jneurosci.org as supplemental material), suggesting larger synaptic conductances at more distal synapses (Jack et al., 1981; Triller et al., 1990; Andrasfalvy and Magee, 2001; Nicholson et al., 2006).

\section{Quantal amplitude at cortical synapses}

The quantal amplitudes we report in this study, measured at the soma, spanned a similar range of amplitudes to previous quantal analysis studies in the cortex [100-800 $\mu \mathrm{V}$ (Torii et al., 1997; Brémaud et al., 2007)]. Regardless of age-dependent differences in synaptic efficacy (Reyes and Sakmann, 1999), our mean $Q$ $(281 \pm 21 \mu \mathrm{V})$ is smaller than that reported for the same neurons in both 2- to 3-week-old cortex (Torii et al., 1997) and adult cortex (Brémaud et al., 2007).

Although values of quantal amplitude varied considerably between connections, the variability of quantal amplitudes within a connection (type 2 quantal variance) was at least small for the $40 \%$ of connections for which we were able to successfully fit quantal models. This observation is supported by studies performed in the rat hippocampus, which showed that the morphologies of non-adjacent dendritic spines innervated by the same presynaptic axon are much more similar than those innervated by different axons (Sorra and Harris, 1993). During development, the quantal properties of synapses experiencing the same presynaptic and postsynaptic activity may converge to similar values (Larkman et al., 1997). In cortex, it has been shown that release probability is similar at the release sites of a given connection (Koester and Johnston, 2005), lending support to this idea. Given that bouton size and PSD area are tightly linked (Schikorski and Stevens, 1997, 1999), this similarity of synaptic properties is therefore likely to extend to quantal size. Many successful quantal analysis studies at a range of central synapses would also suggest this (Stricker et al., 1996; Larkman et al., 1997; Wall and Usowicz, 1998; Hardingham et al., 2006, 2007; Brémaud et al., 2007; Sáez and Friedlander, 2009).

Our distribution of quantal amplitudes is comparable with the amplitude distribution of mEPSPs we recorded from a separate sample of L2/3 neurons. From analysis of the rise times, the two populations (evoked EPSPs and mEPSPs) (supplemental Fig. 8 , available at www.jneurosci.org as supplemental material) are likely to be drawn from similar populations of inputs, primarily from basal and proximal oblique dendrites [which make up $80 \%$ of all the synapses and are subject only to modest cable attenuation (Larkman et al., 1992)]. Comparisons with the distribution of mEPSPs from the model neurons suggests that the major difference is the lack of mEPSPs with a rise time greater than $\sim 8 \mathrm{~ms}$, arising from the distal apical and the apical tuft synapses, consistent with the observation that distal apical inputs are substantially attenuated at the soma and may be hard to detect (Williams and Stuart, 2002). A similar correlation between putative quantal size (derived from evoked EPSCs) and mEPSC amplitude has been reported in electrically compact granule cells from adult cerebellum (Wall and Usowicz, 1998). 


\section{Numbers of release sites and release probability at cortical synapses}

For a subset of connections, we were able to identify putative anatomical contacts from histological preparations. These connections showed a positive correlation between the anatomical and functional estimates of $N$ (derived using quantal analysis). Because silent synapses are unlikely to be common at this age (Rumpel et al., 2004), an identified anatomical contact may very well represent one functional release site (Korn et al., 1981; Gulyás et al., 1993; Silver et al., 2003; Biró et al., 2005) as the vast majority of cortical synapses have been shown to consist of a single structural release site (Schikorski and Stevens, 1999), although evidence for multivesicular release under conditions of high release probability exists at some CNS synapses (Wadiche and Jahr, 2001; Oertner et al., 2002; Christie and Jahr, 2006). For a subset of connected pairs of neurons, we were further able to confirm (using electron microscopy) that these putative contacts were indeed synaptic contacts, but it is possible that some of the contacts identified using light microscopy were erroneous.

Given this caveat, our mean value of $N(3.1 \pm 0.2)$ is also consistent with that reported previously for anatomical connections between L2/3 cortical cells of similar age [2.8 + 0.7 (Feldmeyer et al., 2006) ]. Our mean estimate of release probability $\left(P_{\mathrm{r}}\right)$ for $\mathrm{L} 2 / 3$ to $\mathrm{L} 2 / 3$ connections $(0.47 \pm 0.20)$ is also very close to that derived by optical methods in $\mathrm{L} 2 / 3$ of young rat cortex $[0.46 \pm 0.26$ (Koester and Johnston, 2005) $]$ and also similar to that found from quantal analysis of paired recordings in layer 4 juvenile cortex $[0.41 \pm 0.13$ (Sáez and Friedlander, 2009)] and layer 3 adult cortex $[0.65 \pm 0.18$ (Brémaud et al., 2007)]. The similarity of mean $P_{\mathrm{r}}$ values from the current study with previous estimations of $P_{\mathrm{r}}$ for cortical synapses in turn gives confidence in our estimates of $N$.

\section{Connection strength is set both presynaptically and postsynaptically}

We found that the 70-fold range in connection amplitude was attributable to differences in both presynaptic $(m)$ and postsynaptic ( $Q$ ) strength between connections (Fig. 8). The correlation between presynaptic efficacy $(m)$ and mean EPSP amplitude for L2/3 connections is primarily attributable to $P_{r}$, with little correlation between mean amplitude and $N$. These conclusions are similar to those reached by Markram et al. (1997) for connections between thick tufted L5 neurons and Sáez and Friedlander (2009) for connections between L4 neurons. The connection strength appears to be set in cortex by the strong matching of $P_{\mathrm{r}}$ with $Q$ demonstrated in the present study, which may not be intrinsically fixed but driven by changes in synaptic activity (Thiagarajan et al., 2005; Tokuoka and Goda, 2008).

\section{References}

Alvarez FJ, Dewey DE, Harrington DA, Fyffe RE (1997) Cell-type specific organization of glycine receptor clusters in the mammalian spinal cord. J Comp Neurol 379:150-170.

Andrasfalvy BK, Magee JC (2001) Distance-dependent increase in AMPA receptor number in the dendrites of adult hippocampal CA1 pyramidal neurons. J Neurosci 21:9151-9159.

Atwood HL, Marin L (1983) Ultrastructure of synapses with different transmitter-releasing characteristics on motor axon terminals of a crab, Hyas areneas. Cell Tissue Res 231:103-115.

Bannister NJ, Nelson JC, Jack JJ (2002) Excitatory inputs to spiny cells in layers 4 and 6 of cat striate cortex. Philos Trans R Soc Lond B Biol Sci 357:1793-1808.

Bekkers JM, Stevens CF (1995) Quantal analysis of EPSCs recorded from small numbers of synapses in hippocampal cultures. J Neurophysiol 73:1145-1156.
Biró AA, Holderith NB, Nusser Z (2005) Quantal size is independent of the release probability at hippocampal excitatory synapses. J Neurosci 25:223-232.

Brémaud A, West DC, Thomson AM (2007) Binomial parameters differ across neocortical layers and with different classes of connections in adult rat and cat neocortex. Proc Natl Acad Sci U S A 104:14134-14139.

Christie JM, Jahr CE (2006) Multivesicular release at Schaffer collateralCA1 hippocampal synapses. J Neurosci 26:210-216.

Efron B (1979) Bootstrap methods: another look at the jackknife. Ann Stat $7: 1-26$.

Faber DS, Young WS, Legendre P, Korn H (1992) Intrinsic quantal variability due to stochastic properties of receptor-transmitter interactions. Science 258:1494-1498.

Feldmeyer D, Lübke J, Sakmann B (2006) Efficacy and connectivity of intracolumnar pairs of layer $2 / 3$ pyramidal cells in the barrel cortex of juvenile rats. J Physiol 575:583-602.

Gulyás AI, Miles R, Sík A, Tóth K, Tamamaki N, Freund TF (1993) Hippocampal pyramidal cells excite inhibitory neurons through a single release site. Nature 366:683-687.

Hanse E, Gustafsson B (2001) Quantal variability at glutamatergic synapses in area CAl of the rat neonatal hippocampus. J Physiol 531:467-480.

Hardingham N, Fox K (2006) The role of nitric oxide and GluR1 in presynaptic and postsynaptic components of neocortical potentiation. J Neurosci 26:7395-7404.

Hardingham NR, Larkman AU (1998) Rapid report: the reliability of excitatory synaptic transmission in slices of rat visual cortex in vitro is temperature dependent. J Physiol 507:249-256.

Hardingham NR, Bannister NJ, Read JC, Fox KD, Hardingham GE, Jack JJ (2006) Extracellular calcium regulates postsynaptic efficacy through group 1 metabotropic glutamate receptors. J Neurosci 26:6337-6345.

Hardingham NR, Hardingham GE, Fox KD, Jack JJ (2007) Presynaptic efficacy directs normalization of synaptic strength in layer $2 / 3$ rat neocortex after paired activity. J Neurophysiol 97:2965-2975.

Jack JJ, Redman SJ, Wong K (1981) The components of synaptic potentials evoked in cat spinal motoneurones by impulses in single group Ia afferents. J Physiol 321:65-96.

Jack JJ, Larkman AU, Major G, Stratford KJ (1994) Quantal analysis of the synaptic excitation of CA1 hippocampal pyramidal cells. Adv Second Messenger Phosphoprotein Res 29:275-299.

Katz B (1969) The release of neurotransmitter substances, p 60. Liverpool, UK: Liverpool UP.

Koester HJ, Johnston D (2005) Target cell-dependent normalization of transmitter release at neocortical synapses. Science 308:863-866.

Koester HJ, Sakmann B (2000) Calcium dynamics associated with action potentials in single nerve terminals of pyramidal cells in layer $2 / 3$ of the young rat neocortex. J Physiol 529:625-646.

Korn H, Triller A, Mallet A, Faber DS (1981) Fluctuating responses at a central synapse: $n$ of binomial fit predicts number of stained presynaptic boutons. Science 213:898-901.

Larkman AU (1991) Dendritic morphology of pyramidal neurones of the visual cortex of the rat. III. Spine distributions. J Comp Neurol 306: 332-343.

Larkman AU, Major G, Stratford KJ, Jack JJ (1992) Dendritic morphology of pyramidal neurones of the visual cortex of the rat. IV. Electrical geometry. J Comp Neurol 323:137-152.

Larkman AU, Jack JJ, Stratford KJ (1997) Quantal analysis of excitatory synapses in rat hippocampal CA1 in vitro during low-frequency depression. J Physiol 505:457-471.

Lim R, Alvarez FJ, Walmsley B (1999) Quantal size is correlated with receptor cluster area at glycinergic synapses in the rat brainstem. J Physiol 516:505-512.

Liu G, Choi S, Tsien RW (1999) Variability of neurotransmitter concentration and nonsaturation of postsynaptic AMPA receptors at synapses in hippocampal cultures and slices. Neuron 22:395-409.

Magee JC, Cook EP (2000) Somatic EPSP amplitude is independent of synapse location in hippocampal pyramidal neurons. Nat Neurosci 3:895-903.

Major G (1993) Solutions for transients in arbitrarily branching cables. III. Voltage clamp problems. Biophys J 65:469-491.

Major G, Larkman AU, Jonas P, Sakmann B, Jack JJ (1994) Detailed passive cable models of whole-cell recorded CA3 pyramidal neurons in rat hippocampal slices. J Neurosci 14:4613-4638. 
Markram H, Lübke J, Frotscher M, Roth A, Sakmann B (1997) Physiology and anatomy of synaptic connections between thick tufted pyramidal neurones in the developing rat neocortex. J Physiol 500:409-440.

McAllister AK, Stevens CF (2000) Nonsaturation of AMPA and NMDA receptors at hippocampal synapses. Proc Natl Acad Sci USA 97:6173-6178.

Murthy VN, Schikorski T, Stevens CF, Zhu Y (2001) Inactivity produces increases in neurotransmitter release and synapse size. Neuron 32:673682.

Nevian T, Larkum ME, Polsky A, Schiller J (2007) Properties of basal dendrites of layer 5 pyramidal neurons: a direct patch-clamp recording study. Nat Neurosci 10:206-214.

Nicholson DA, Trana R, Katz Y, Kath WL, Spruston N, Geinisman Y (2006) Distance-dependent differences in synapse number and AMPA receptor expression in hippocampal CA1 pyramidal neurons. Neuron 50:431-442.

Nusser Z, Lujan R, Laube G, Roberts JD, Molnar E, Somogyi P (1998) Cell type and pathway dependence of synaptic AMPA receptor number and variability in the hippocampus. Neuron 21:545-559.

Oertner TG, Sabatini BL, Nimchinsky EA, Svoboda K (2002) Facilitation at single synapses probed with optical quantal analysis. Nat Neurosci 5:657-664.

Peters A, Sethares C, Harriman KM (1990) Different kinds of axon terminals forming symmetric synapses with the cell bodies and initial axon segments of layer II/III pyramidal cells. II. Synaptic junctions. J Neurocytol 19:584-600.

Rall W (1960) Membrane potential transients and membrane time constant of motoneurons. Exp Neurol 2:503-532.

Reyes A, Sakmann B (1999) Developmental switch in the short-term modification of unitary EPSPs evoked in layer 2/3 and layer 5 pyramidal neurons of rat neocortex. J Neurosci 19:3827-3835.

Rollenhagen A, Lübke JH (2006) The morphology of excitatory central synapses: from structure to function. Cell Tissue Res 326:221-237.

Rumpel S, Kattenstroth G, Gottmann K (2004) Silent synapses in the immature visual cortex: layer-specific developmental regulation. J Neurophysiol 91:1097-1101.

Sáez I, Friedlander MJ (2009) Synaptic output of individual layer 4 neurons in guinea pig visual cortex. J Neurosci 29:4930-4944.

Schikorski T, Stevens CF (1997) Quantitative ultrastructural analysis of hippocampal excitatory synapses. J Neurosci 17:5858-5867.

Schikorski T, Stevens CF (1999) Quantitative fine-structural analysis of olfactory cortical synapses. Proc Natl Acad Sci U S A 96:4107-4112.

Silver RA, Lubke J, Sakmann B, Feldmeyer D (2003) High-probability uniquantal transmission at excitatory synapses in barrel cortex. Science 302:1981-1984.

Sorra KE, Harris KM (1993) Occurrence and three-dimensional structure of multiple synapses between individual radiatum axons and their target pyramidal cells in hippocampal area CA1. J Neurosci 13:3736-3748.
Stratford KJ, Mason AJR, Larkman AU, Major G, Jack JJB (1989) The modelling of pyramidal neurones in the visual cortex. In: The computing neurone (Durbin R, Miall C, Mitchison G, ed), pp 296-321. New York: Addison-Wesley.

Stratford KJ, Jack JJ, Larkman AU (1997) Calibration of an autocorrelationbased method for determining amplitude histogram reliability and quantal size. J Physiol 505:425-442.

Stricker C, Redman S, Daley D (1994) Statistical analysis of synaptic transmission: model discrimination and confidence limits. Biophys J 67:532547.

Stricker C, Field AC, Redman SJ (1996) Statistical analysis of amplitude fluctuations in EPSCs evoked in rat CA1 pyramidal neurones in vitro. J Physiol 490:419-441.

Stuart G, Spruston N (1998) Determinants of voltage attenuation in neocortical pyramidal neuron dendrites. J Neurosci 18:3501-3510.

Takumi Y, Ramírez-León V, Laake P, Rinvik E, Ottersen OP (1999) Different modes of expression of AMPA and NMDA receptors in hippocampal synapses. Nat Neurosci 2:618-624.

Tanaka J, Matsuzaki M, Tarusawa E, Momiyama A, Molnar E, Kasai H, Shigemoto R (2005) Number and density of AMPA receptors in single synapses in immature cerebellum. J Neurosci 25:799-807.

Thiagarajan TC, Lindskog M, Tsien RW (2005) Adaptation to synaptic inactivity in hippocampal neurons. Neuron 47:725-737.

Tokuoka H, Goda Y (2008) Activity-dependent coordination of presynaptic release probability and postsynaptic GluR2 abundance at single synapses. Proc Natl Acad Sci U S A 105:14656-14661.

Torii N, Tsumoto T, Uno L, Astrelin AV, Voronin LL (1997) Quantal analysis suggests presynaptic involvement in expression of neocortical shortand long-term depression. Neuroscience 79:317-321.

Trevelyan AJ, Jack J (2002) Detailed passive cable models of layer 2/3 pyramidal cells in rat visual cortex at different temperatures. J Physiol 539:623-636.

Triller A, Seitanidou T, Franksson O, Korn H (1990) Size and shape of glycine receptor clusters in a central neuron exhibit a somato-dendritic gradient. New Biol 2:637-641.

Wadiche JI, Jahr CE (2001) Multivesicular release at climbing fiber-Purkinje cell synapses. Neuron 32:301-313.

Wahl LM, Stratford KJ, Larkman AU, Jack JJ (1995) The variance of successive peaks in synaptic amplitude histograms: effects of inter-site differences in quantal size. Proc Biol Sci 262:77-85.

Wall MJ, Usowicz MM (1998) Development of the quantal properties of evoked and spontaneous synaptic currents at a brain synapse. Nat Neurosci 1:675-682.

Walmsley B, Alvarez FJ, Fyffe RE (1998) Diversity of structure and function at mammalian central synapses. Trends Neurosci 21:81-88.

Williams SR, Stuart GJ (2002) Dependence of EPSP efficacy on synapse location in neocortical pyramidal neurons. Science 295:1907-1910. 